\section{Near-fatal asphyxia by a toy shopping bag}

The risk of asphyxia by polythene bags is well recognised and such bags carry a warning against children using them as toys. We report an instance of near-fatal asphyxia in a $2 \frac{1}{2}$-year-old child by a "shopping bag" being accidentally pulled over her head. The bag was made of polyvinylchloride and cotton and is sold for use by children (see figure).

\section{Case report}

A $2 \frac{1}{2}$-year-old girl was found by her mother slumped to the floor, cyanosed, floppy, and unconscious, with the toy shopping bag pulled over her face. The bag was fitting tightly over her face with the lower end reaching the chin. The child had been unattended for only about five minutes. When seen in the casualty department about 20 minutes later she was unconscious with stertorous breathing. The tone in all four limbs was increased. Pupils were equal and reacted to light. Fundoscopy was not done in the casualty department. The child's blood sugar concentration at the time was $12.5 \mathrm{mmol} / 1$ $(225 \mathrm{mg} / 100 \mathrm{ml})$. She was given diazepam $3 \mathrm{mg}$ intravenously.

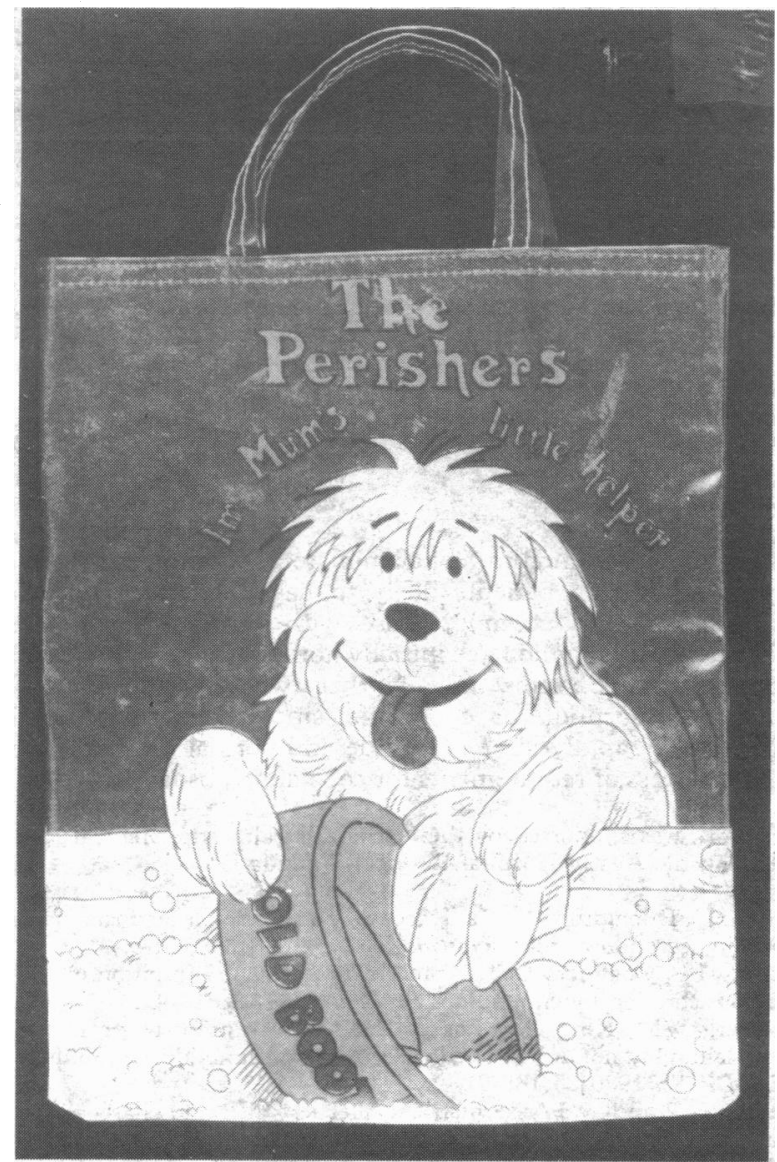

Photograph of bag.

The child was seen by one of us (DTDB) about 15 minutes later. She was comatose with response only to painful stimuli; she had no fever. Pupils were equal and reacted to light. Both fundi showed considerably engorged veins but no papilloedema. Tone was increased in all four limbs, deep reflexes were brisk, and plantar response was flexor on both sides. There was no cyanosis. Pulse was $120 / \mathrm{min}$ and there were no signs of cardiac decompensation. Breathing was deep and stertorous. No adventitious sounds were heard over the lungs. Blood pH was $7 \cdot 30$ with $\mathrm{PCO}_{2} 5 \cdot 7 \mathrm{kPa}$ $(43 \mathrm{~mm} \mathrm{Hg})$ and base excess $-5.4 \mathrm{mmol}(\mathrm{mEq}) / 1$. Haemoglobin concentration was $12.2 \mathrm{~g} / \mathrm{dl}$ with a white blood count of $9.3 \times 10^{9} / 1$ and erythrocyte sedimentation rate of $27 \mathrm{~mm}$ in first hour. Urea concentration was $6.0 \mathrm{mmol} / 1$ $(36 \mathrm{mg} / 100 \mathrm{ml})$, sodium $136 \mathrm{mmol}(\mathrm{mEq}) / \mathrm{l}$, and potassium $3.6 \mathrm{mmol}(\mathrm{mEq}) / \mathrm{l}$. Cerebral oedema secondary to asphyxia was diagnosed and the child given $150 \mathrm{ml}$ of $20 \%$ mannitol solution over 30 minutes (child's weight $14 \mathrm{~kg}$ ). Her level of consciousness improved rapidly in about 45 minutes and she was able to take a drink of water. Blood sugar measured three hours after admission was normal. Results of liver function tests were normal. Twelve hours after admission the child was well without any sequelae and was sent home.

\section{Comment}

The hyperglycaemia observed in our patient did not last long and could have resulted from the stress response to asphyxia and the release of catecholamines from the adrenal medulla. ${ }^{1}$ Though no papilloedema was observed the rapid improvement in the level of consciousness after the mannitol infusion suggested some degree of cerebral oedema, which is a well-recognised complication of asphyxia. ${ }^{2}$

The bag, made of polyvinylchloride with cotton lining (55\% polyvinylchloride, $45 \%$ cotton), was of such dimensions $(0.4 \mathrm{~mm}$ thick, $365 \mathrm{~mm}$ wide, and $330 \mathrm{~mm}$ deep) that if accidentally pulled over a young child's head, as in this case, would cause a tight fit and lead to asphyxia.

Improperly designed and manufactured toys are a known hazard to children and the Toys (Safety) Regulations Act $1974^{3}$ was meant to eliminate such hazards. These regulations make specific reference to plastic bags and require the manufacturers to display a warning that such bags, if less than $38 \mu \mathrm{m}$ thick, are dangerous to children and should be kept away from them. Clearly the thin-walled plastic bags are a hazard to children, since such a bag accidentally pulled over a child's face could be sucked in during inspiration leading to suffocation. The makers of the polyvinylchloride and cotton bag that caused asphyxia in our patient (helenware) have not contravened the Toys (Safety) Regulations as the bag was more than $38 \mu \mathrm{m}$ in thickness. The experience with our patient, however, shows that when the dimensions of a bag made of material impervious to air are such that it could cause a tight fit over a young child's face then severe asphyxia may result even when the wall of the bag is more than $38 \mu \mathrm{m}$ in thickness.

A warning as to the non-suitability of a bag of this size for small children may have avoided this near fatality. We suggest that the Toys (Safety) Regulations be extended to require manufacturers to display a warning of hazard to children for bags made of material impervious to air if the dimensions are such that they could cause a tight fit over a young child's face.

Parents should be careful when buying toys for young children and should consider the suitability of the toy to the child's age group.

1 Nelson WE. Textbook of paediatrics. 11th ed. Philadelphia and London: W B Saunders, 1979:423.

${ }^{2}$ Keele CA, Neill E, revisers. Samson Wright's applied physiology. 12th ed. Oxford: Oxford University Press, 1971:397.

${ }^{3}$ Statutory Publications Office. Toys (Safety) Regulations Act. London: HMSO, 1974:361-5. (SI No 1367.)

(Accepted 6 May 1982)

Rotherham District General Hospital, Rotherham S60 2UD

D T D BULUGAHAPITYA, FRCP, DCH, consultant paediatrician P R BECK, PHD, MB, consultant clinical biochemist

SANDRA LOBO, MB, BS, senior house officer in paediatrics

\section{Meningitis caused by dysgonic fermenter type 2 (DF 2) organism in a previously healthy adult}

In 1977 Butler et al described a "new" disease in man caused by an unidentified Gram-negative bacillus. Fifteen of their 17 patients were male adults and 14 had underlying conditions including previous splenectomy. In 10 cases the illness was preceded by a recent dog bite. The clinical syndromes included cellulitis, primary bacteraemia without localisation, purulent meningitis, and endocarditis. The organism has subsequently been classified as a dysgonic fermenter type 2 (DF 2, Atlanta classification).

Recently, septicaemia due to this organism was complicated by classical Waterhouse-Friderichsen syndrome in a patient having 
previously undergone splenectomy. ${ }^{2}$ We report a case of meningitis caused by this organism in an otherwise healthy woman.

\section{Case report}

A 66-year-old previously healthy Caucasian woman was admitted with a history of fever, myalgia, and malaise for two days and of severe headache for one. She developed photophobia, vomiting, neck stiffness, and a rash on the day of admission. She denied recent trauma or infection but remarked that she and her husband had cleaned out the drains round their house just before she became ill. She frequently played with their pet dog but had never been bitten.

On admission she was pyrexial with clinical signs of meningitis and a macular rash confined to the trunk. Other findings were blood white cell count $10.8 \times 10^{9} / 1$ with $8.9 \times 10^{9} / 1$ neutrophils. Chest $x$-ray films showed bilateral basal collapse. Lumbar puncture yielded cloudy cerebrospinal fluid under slightly increased pressure with a white cell count of $575 \times 10^{6} / 1$ (nearly all polymorphonuclear leucocytes), protein content $2.4 \mathrm{~g} / \mathrm{l}$, and glucose $<1.25 \mathrm{mmol} / 1(22.52 \mathrm{mg} / 100 \mathrm{ml})$. Blood glucose was $5.2 \mathrm{mmol} / \mathrm{l}$ $(93.70 \mathrm{mg} / 100 \mathrm{ml})$. Gram-stained films of cerebrospinal fluid deposit showed large numbers of slender Gram-negative bacilli. Cultures yielded a fastidious Gram-negative bacillus after five days' incubation on Columbia blood agar in an atmosphere containing 7\% carbon dioxide. A similar organism was also isolated from blood cultures taken on the day of admission after prolonged incubation of subcultures in an atmosphere of $7 \%$ carbon dioxide. Both isolates were finally identified as a dysgonic fermenter type 2 by the Center for Disease Control (Atlanta, Georgia, USA).

She was treated for three days with intravenous benzylpenicillin 2 megaunits four hourly and intravenous chloramphenicol $750 \mathrm{mg}$ eight hourly. On day 4 the chloramphenicol regimen was changed to $500 \mathrm{mg}$ orally six hourly, and on day 7 penicillin was discontinued. Chloramphenicol was continued until the tenth day, by which time the patient had been apyrexial for three days and was symptom free. On discharge three days later her recovery was complete with no neurological deficit and chest $x$-ray films showing only minimal linear collapse in the right lower lobe.

\section{Comment}

Of the 17 cases reported by Butler et al $l^{1}$ only two resembled our case in having previously been healthy and without a history of dog bite. Like ours, two of their 17 patients presented with purulent meningitis, but their previous state of health was not reported. Pulmonary infiltration was present in six of Butler's cases, but there was no instance of a macular rash. In our case large numbers of Gramnegative bacilli were seen in the smears of cerebrospinal fluid, and when no organisms had grown on culture after three days the plates were further incubated until growth appeared five days later. The blood subcultures also received prolonged incubation. Had the organism been present only in the blood we might have failed entirely to grow it. For this reason we suspect, as do Butler et al, ${ }^{2}$ that bacteraemia due to a dysgonic fermenter type 2 organism is probably considerably underdiagnosed.

1 Butler T, Weaver RE, Venkata-Ramani TK, et al. Unidentified Gramnegative rod infection-a new disease of man. Ann Intern Med 1977; $86: 1-5$.

${ }^{2}$ Chaudhuri AK, Hartley RB, Maddocks AC. Waterhouse-Friderichsen syndrome caused by a DF-2 bacterium in a splenectomised patient. f Clin Pathol 1981 ;34:172-3.

(Accepted 4 May 1982)

Infectious Diseases Unit, Hither Green Hospital, London SE13

D OFORI-ADJEI, MRCP, registrar

P BLACKLEDGE, FRCP, consultant physician

$P$ O'NEILL, DM, consultant microbiologist

\section{Effect of chronic ranitidine treatment on secretion of intrinsic factor}

The gastric parietal cell secretes both acid and intrinsic factor, and so there has been concern that treatment with histamine $\mathrm{H}_{2}$-receptor antagonists might lead to reduced secretion of intrinsic factor and hence to cobalamin (vitamin $\mathrm{B}_{12}$ ) deficiency. Cimetidine transiently inhibits secretion of intrinsic factor, ${ }^{2}{ }^{2}$ and Steinberg et $a l^{3}$ found decreased absorption of protein-bound cobalamin. There is no evidence as yet, however, of clinical cobalamin deficiency developing as a result of treatment with cimetidine. We studied secretion of intrinsic factor in patients receiving ranitidine.

\section{Patients, methods, and results}

We measured the secretion of intrinsic factor in patients aged 31-61 years receiving a six-week course of ranitidine $300 \mathrm{mg} /$ day for duodenal ulcer. Output of intrinsic factor and the concentration of intrinsic factor in gastric juice were measured by radioimmunoassay using the method of Gottlieb et al. ${ }^{4}$ Three studies were performed on each patient-namely, before, during (at five weeks), and one week after treatment. Basal and pentagastrin-stimulated $(6 \mu \mathrm{g} / \mathrm{kg} / \mathrm{h}$ intravenously) outputs of intrinsic factor were measured. In addition, one hour after the pentagastrin infusion was started ranitidine ( 150 $\mathrm{mg}$ ) was given intravenously and output of intrinsic factor measured for a further two hours.

The table summarises the results. Basal output of intrinsic factor, which during treatment was measured before the morning dose (10-12 hours after the evening dose), was statistically similar to output in the pretreatment and post-treatment studies. Thus during treatment there was no evidence of

Mean $( \pm S E M)$ output of intrinsic factor $(k U / h)$ in four patients

\begin{tabular}{lcccc}
\hline \multirow{2}{*}{ Study* } & \multirow{2}{*}{ Basal } & $\begin{array}{c}\text { Pentagastrin- } \\
\text { stimulated }\end{array}$ & \multicolumn{2}{c}{ After ranitidine $\dagger$} \\
\cline { 4 - 5 } & & $0-60 \mathrm{~min}$ & $60-120 \mathrm{~min}$ \\
\hline 1 & $0.68 \pm 0.26$ & $2.96 \pm 0.47$ & $0.08 \pm 0.06$ & $0.53 \pm 0.30$ \\
2 & $1.32 \pm 0.44$ & $4.67 \pm 1.10$ & $0.10 \pm 0.04$ & $1.35 \pm 0.42 \ddagger$ \\
3 & $0.81 \pm 0.21$ & $3.61 \pm 0.73$ & $0.07 \pm 0.03$ & $0.20 \pm 0.06$
\end{tabular}

*Study 1, before ranitidine treatment; study 2, during treatment; study 3, 1-2 weeks

after treatment.

$\ddagger \mathrm{p}<0.05$ (compared with studies 1 and 3 ; analysis of variance, Wilcoxon test).

persistent inhibition from the previous dose. Pentagastrin-stimulated output was also similar in the three studies. After an intravenous bolus of ranitidine output dropped dramatically for the first hour and then quickly returned toward basal values. This return in the second hour was significantly faster during treatment than before or after.

\section{Comment}

It may be wise to monitor cobalamin stores if long-term ranitidine treatment is used in patients likely to have impaired secretion of intrinsic factor-for example, those with severe fundic gastritis. In the great majority who have initially normal production of intrinsic factor, however, it seems unlikely that twice-daily ranitidine will produce malabsorption of cobalamin since secretion of intrinsic factor recovers rapidly after ranitidine and normal rates of secretion are well in excess of requirements for cobalamin absorption. ${ }^{5}$

This work was supported by the National Health and Medical Research Council and the Austin Hospital Research Foundation.

1 Binder HJ, Donaldson RM Jr. Effect of cimetidine on intrinsic factor and pepsin secretion in man. Gastroenterology 1978;74:371-5.

2 Fielding LP, Chalmers DM, Chanarin I, Levi AJ. Inhibition of intrinsic factor secretion by cimetidine. Br Med $\mathcal{f} 1978 ; \mathrm{i}: 818-9$.

${ }^{3}$ Steinberg WM, King CE, Toskes PP. Malabsorption of protein-bound cobalamin but not unbound cobalamin during cimetidine administration. Dig Dis Sci $1980 ; 25: 188-91$.

${ }^{4}$ Gottlieb C, Lau KS, Wasserman LR, Herbert V. Rapid charcoal assay for intrinsic factor (IF), gastric juice unsaturated $B_{12}$ binding capacity, antibody to IF, and serum unsaturated $\mathrm{B}_{12}$ binding capacity. Blood $1965 ; 25: 875-84$

${ }^{5}$ Ardeman S, Chanarin I, Doyle JC. Studies on secretion of gastric intrinsic factor in man. $\mathrm{Br} M e d \mathcal{F} 1964$;ii:600-3.

(Accepted 28 April 1982)

Departments of Gastroenterology and Clinical Pharmacology, Division of Medicine, Austin Hospital, Melbourne, Victoria 3084, Australia

N D YEOMANS, FRACP, senior lecturer in medicine, University of Melbourne

R G HANSON, FRACP, gastroenterology fellow

R A SMALLWOOD, FRACP, director of gastroenterology

G W MIHALY, PHD, senior research officer

W J LOUIS, FRACP, professor of clinical pharmacology and therapeutics, University of Melbourne

(2)

